Terr. Atmos. Ocean. Sci., Vol. 17, No. 3, 593-612, September 2006

\title{
Sensitivity Study of the Climate Simulation over East Asia with the CWB Regional Spectral Model
}

\author{
Chih-Hui Shiao ${ }^{1, *}$ and Hann-Ming Henry Juang ${ }^{2}$
}

(Manuscript received 1 March 2004, in final form 1 August 2006)

\begin{abstract}
How accurate is the Taiwan Central Weather Bureau (CWB) regional spectral model (RSM)? An assessment is conducted by numerical simulation of Mei-Yu fronts and their associated precipitation patterns during May to August of 1998 using CWB RSM, driven by analysis from the CWB global forecast system.

For this assessment, three episodes of East Asian Summer Monsoon heavy rainfall shown by Ding and Liu (2001) and an additional transition period from 26 May to 10 June were chosen to test the respective roles of domain size and model resolution sensitivity. Results indicate that the small domain ( $\sim 3500$ by $\left.3000 \mathrm{~km}^{2}\right)$ simulation, but not the larger domain $(\geq 7000$ by $6000 \mathrm{~km}^{2}$ ) simulations, simulated the monsoon and Mei-Yu front heavy precipitation events accurately for all of the above periods.

By comparing experimental results from various combinations of domain size and model resolution, we demonstrate that the simulated largescale circulation and precipitation distribution were more sensitive to model domain size than to model horizontal resolution, whereas finer structures could only be achieved in the higher resolution simulations. Local characteristics of the precipitation over Taiwan Island, especially over the Central Mountains, were reasonably reproduced in the $20 \mathrm{~km}$ resolution simulation in terms of averages taken during the transition period and over the seasonal period from May to August. However, the CWB RSM with 20 km resolution might still be insufficient to resolve the severe precipitation events in southern Taiwan.
\end{abstract}

(Key words: CWB RSM, Regional climate simulation, East Asian)

\footnotetext{
${ }^{1}$ Research and Development Center, Central Weather Bureau, Taipei, Taiwan, ROC

2 Environmental Modeling Center, National Centers for Environmental Prediction, Washington DC

* Corresponding author address: Dr. Chih-Hui Shiao, Research and Development Center, Central Weather Bureau, Taipei, Taiwan, ROC; E-mail: gfs12@rdc.cwb.gov.tw
} 


\section{INTRODUCTION}

In recent years, regional models have become a useful tool for providing regional climate details when nested inside a lower-resolution global model or driven by reanalysis for regional climate studies (Dickinson et al. 1989; Giorgi and Bates 1989; Liu et al. 1994).

The treatment of the lateral boundary, which supplies climate-scale forcing to the model, is one of the major problems in regional climate modeling. To provide more outer information for the regional model, a broader lateral boundary zone is often used, such as the method employed by Giorgi et al. (1993), whose model was based on the National Center for Atmospheric Research/Pennsylvania State University (NCAR/PSU) mesoscale model. Spectral nesting or filtering is another method used by Kida et al. (1991), von Storch et al. (1993) and Waldron et al. (1996).

The National Center for Environmental Prediction (NCEP) Regional Spectral Model (RSM) developed by Juang and Kanamitsu (1994), updated by Juang et al. (1997), Hong and Juang (1998), and Juang and Hong (2001), defined prognostic variables in the entire regional domain as a summation of perturbation and base fields. The base field is a time-dependent prediction or analysis from the global model, and the perturbation is the deviation of the full value predicted by the regional model from the forcing base field. The nesting strategy, or so-called "domain nesting", through the partitioning of perturbation and base field, may be one of NCEP RSM's advantages for avoiding "climate drift", since the model simulation is constantly on the track of the prescribed base fields covering the entire domain. Thus, instead of a large buffer zone, a narrow zone with relaxation along the lateral boundary is sufficient to handle the lateral boundary conditions.

The sensitivity of boundary forcing is another critical issue for both mid-latitude and tropical area regional climate studies, especially for the study of the East Asian Monsoon. For example, the regional model domain should be large enough to include the remote heat sources, such as the Tibetan Plateau, the Indian subcontinent, the Bay of Bengal, and the Arabian Sea (Ji and Vernekar 1997; Lau et al. 1998) to simulate the evolution of East Asian Monsoon accurately. However, Jones et al. (1995) showed that when a domain is large enough to generate large-scale forcing, the regional model large-scale features might drift away from the driving data. Conversely, a smaller domain confines the interior solution more toward the coarse driving fields, which may also yield an unrealistic responses to internal higher resolution forcing.

Not only is the area of the regional model domain critical, the model resolution is a decisive factor as well. The resolution should be as fine as possible to resolve dynamical effects such as the complexity of shoreline and topography (Kato et al. 1999; Gong and Wang 2000). Therefore, realistic simulation for the monsoon system over East Asia still presents a great challenge for current regional climate modeling.

For the purpose of making regional climate downscaling forecasts, a new regional spectral model, CWB RSM, based on the CWB global spectral model (GSM) and NCEP RSM, is being developed at the Taiwan Central Weather Bureau by Juang et al. (2003). Our objective in this study is to assess the capability of CWB RSM by examining its sensitivities to the model domains and horizontal resolutions on the summer monsoon evolution over East Asia, particularly over the Taiwan area, during 1998. A short description of the CWB RSM is given 
in section 2. Section 3 presents a review of the heavy precipitation events of the monsoon evolution. Section 4 describes the experiment designs. The sensitivity tests and results are illustrated in section 5. Conclusions and discussion are provided in the last section.

\section{DESCRIPTION OF THE CWB RSM}

In short, the model structure, dynamics, and physics of the CWB RSM are based on the CWB GSM, the current operational weather prediction global model at CWB. The CWB RSM is a hydrostatic, primitive equation model on sigma coordinates. The prognostic equations are horizontal momentum equations, virtual potential temperature, specific humidity, and surface pressure with the advection form. The model physics are all adopted from the CWB GSM, including the parameterization of surface fluxes, vertical turbulence mixing of K-theory, shortwave and longwave radiation transfer, cumulus convection, Tiedke-type non-precipitation shallow convection, grid-scale condensation and gravity wave drag parameterization. The detailed description of the model physics was shown in Liou et al. (1997).

The perturbation concept and the nesting strategy from NCEP RSM are duplicated in CWB RSM. In order to smooth the performance along the lateral boundaries, the model uses the implicit relaxation and orography blending proposed by Hong and Juang (1998) and Juang and Hong (2001). A detailed description of CWB RSM can be found in Juang et al. (2003).

\section{THE ONSET AND EVOLUTION OF THE EAST ASIAN SUMMER MONSOON 1998}

The onset and evolution of the 1998 East Asian Summer Monsoon over China, as described in Ding and Liu (2001) and Wang et al. (2003), included three episodes: the onset of East Asian Monsoon over the South China Sea (SCS) during 17 - 25 May, the first Mei-Yu that approached the Yangtze River Basin from 12 June - 4 July, and the second Mei-Yu (17 31 July) over the Yangtze River Basin. Severe precipitation events were associated with all three episodes.

An additional episode in this study, 26 May to 10 June, constituted the transition period between the monsoon onset over the SCS and the first Mei-Yu visit to the Yangtze River Basin. Heavy rainfall occurred over southern Taiwan when the major monsoon rain belt approached.

The 1998 summer monsoon evolution as described by the Global Precipitation Climatology Project (GPCP) daily precipitation analysis data (Huffman et al. 1997), and the CWB Global Forecast System (GFS) analysis of mean sea level pressure (MSLP) is given in Figs. 1a - 1h for the temporal averages of the above four episodes. The left panel is the rainfall rate analysis from the GPCP with $1^{\circ} \times 1^{\circ}$ resolution and the right panel is the mean sea level pressure with $1.5^{\circ} \times 1.5^{\circ}$ resolution from the global atmospheric analysis data of CWB GFS. Only events within the area $105^{\circ}-135^{\circ} \mathrm{E}$ and $10^{\circ}-35^{\circ} \mathrm{N}$ are presented.

Analysis of the onset period (Figs. 1a and b) shows that two rainfall zones were organized along the NE-SW direction over East Asia. A primary surface monsoon trough was associated 
(a)

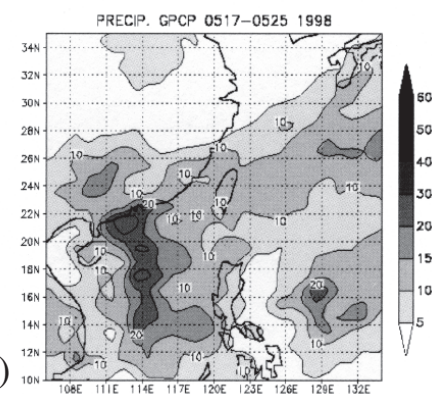

(c)

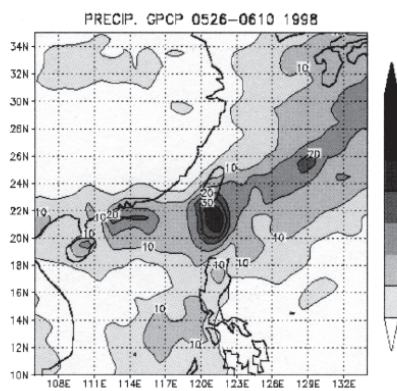

(e)

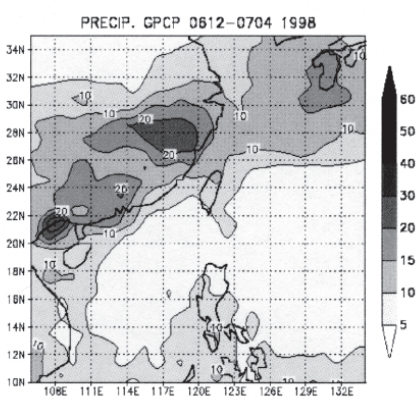

(g)

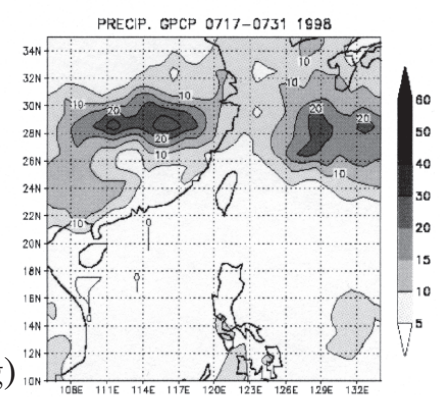

(b)

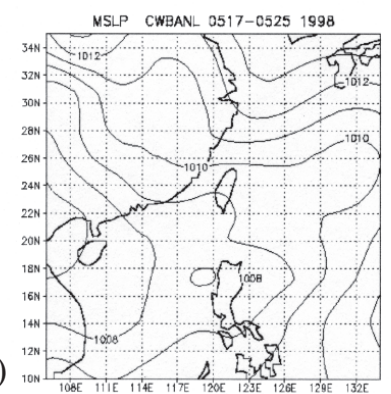

(d)

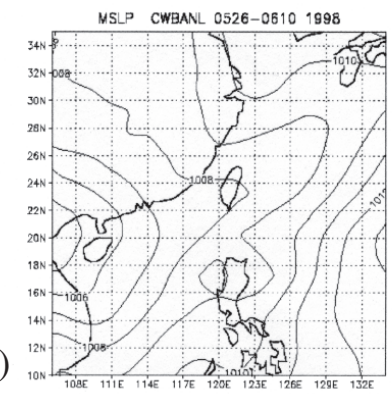

(f)

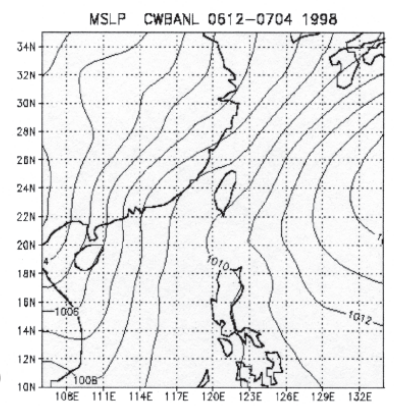

NSLP CWHANL 0717-0731 1998

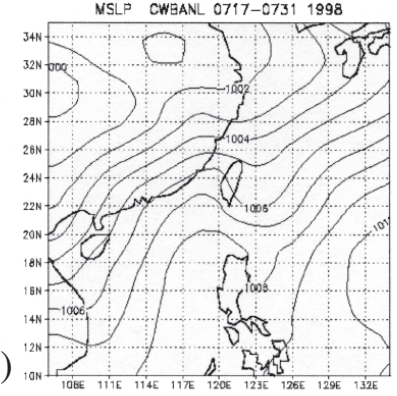

Fig. 1. Horizontal distribution of period-averaged GPCP precipitation (left panels) and CWB GFS mean sea level pressure analysis (right panels) over East Asia. The included periods are: $(\mathrm{a}, \mathrm{b})$ the monsoon onset, May 17 - 25, (c, d) the transition, May 26 to June 10, (e, f) the first Mei-Yu, June 12 to July 4, (g, h) the second Mei-Yu, July 17 - 31, 1998. Units are mm day ${ }^{-1}$ in the left panels and $\mathrm{hPa}$ in the right panels. 
with a rainfall zone spread from the SCS, passing through the Taiwan area, and reaching southern Japan. The southern rain branch within the weaker secondary surface pressure trough extended from the SCS to the eastern shore of the Philippines. Heavy rainfall over the SCS and the established surface pressure troughs were dominant features during the East Asian Summer Monsoon onset period.

During the transition period of May 26 to June 10, an organized rainfall belt covered the northern SCS to southern Japan. The rainfall rate increased over the western Pacific, but decreased over the SCS (Fig. 1c) compared to the previous period. This change in the precipitation pattern was associated with a strengthened surface pressure trough which extended a few degrees further northeastward to the western Pacific (Fig. 1d). In the same period, a heavy precipitation event was observed over southern Taiwan by GPCP, and events with daily rainfall exceeding $200 \mathrm{~mm}$ were reported at the CWB stations of Hengchun, Tawu and Kaoshiung. The CWB station names and geographic locations are listed in Table 1 for reference.

Table 1. List of CWB station names and geographic locations.

\begin{tabular}{|c|c|c|}
\hline Station Number & Station Name & Location \\
\hline 466900 & Tanshui & $121^{\circ} 26^{\prime} 24.00^{\prime \prime}$ E $25^{\circ} 09^{\prime} 56.00^{\prime \prime} \mathrm{N}$ \\
\hline 466920 & Taipei & $121^{\circ} 30^{\prime} 24.15^{\prime \prime}$ E $25^{\circ} 02^{\prime} 22.62^{\prime \prime} \mathrm{N}$ \\
\hline 466940 & Keelung & $121^{\circ} 43^{\prime} 55.66^{\prime \prime}$ E $25^{\circ} 08^{\prime} 05.18^{\prime \prime} \mathrm{N}$ \\
\hline 466950 & Pengchiayu & $122^{\circ} 04^{\prime} 16.52^{\prime \prime}$ E $25^{\circ} 37^{\prime} 45.99^{\prime \prime} \mathrm{N}$ \\
\hline 466990 & Hualien & $121^{\circ} 36^{\prime} 17.98^{\prime \prime}$ E $23^{\circ} 58^{\prime} 37.10^{\prime \prime} \mathrm{N}$ \\
\hline 467060 & Suao & $121^{\circ} 52^{\prime} 00.00^{\prime \prime}$ E $24^{\circ} 36^{\prime} 00.00^{\prime \prime} \mathrm{N}$ \\
\hline 467080 & Ilan & $121^{\circ} 44^{\prime} 52.55^{\prime \prime}$ E $24^{\circ} 45^{\prime} 56.04^{\prime \prime} \mathrm{N}$ \\
\hline 467350 & Penghu & $119^{\circ} 33^{\prime} 18.71^{\prime \prime}$ E $23^{\circ} 34^{\prime} 01.84^{\prime \prime} \mathrm{N}$ \\
\hline 467410 & Tainan & $120^{\circ} 11^{\prime} 49.18^{\prime \prime}$ E $22^{\circ} 59^{\prime} 42.81^{\prime \prime} \mathrm{N}$ \\
\hline 467440 & Kaoshiung & $120^{\circ} 18^{\prime} 28.92^{\prime \prime}$ E $22^{\circ} 34^{\prime} 04.40^{\prime \prime} \mathrm{N}$ \\
\hline 467480 & Chiayi & $120^{\circ} 25^{\prime} 00.00^{\prime \prime}$ E $23^{\circ} 30^{\prime} 00.00^{\prime \prime} \mathrm{N}$ \\
\hline 467490 & Taichung & $120^{\circ} 40^{\prime} 33.31^{\prime \prime}$ E $24^{\circ} 08^{\prime} 50.98^{\prime \prime} \mathrm{N}$ \\
\hline 467530 & Alishan & $120^{\circ} 48^{\prime} 18.39^{\prime \prime}$ E $23^{\circ} 30^{\prime} 37.42^{\prime \prime} \mathrm{N}$ \\
\hline 467540 & Tawu & $120^{\circ} 53^{\prime} 44.48^{\prime \prime}$ E $22^{\circ} 21^{\prime} 27.26^{\prime \prime} \mathrm{N}$ \\
\hline 467570 & Hsinchu & $120^{\circ} 58^{\prime} 10.45^{\prime \prime}$ E $24^{\circ} 48^{\prime} 07.99^{\prime \prime} \mathrm{N}$ \\
\hline 467590 & Hengchun & $120^{\circ} 44^{\prime} 16.99^{\prime \prime}$ E $22^{\circ} 00^{\prime} 19.56^{\prime \prime} \mathrm{N}$ \\
\hline 467610 & Chengkung & $121^{\circ} 21^{\prime} 55.36^{\prime \prime}$ E $23^{\circ} 05^{\prime} 57.17^{\prime \prime} \mathrm{N}$ \\
\hline 467620 & Lanyu & $121^{\circ} 33^{\prime} 02.10^{\prime \prime}$ E $22^{\circ} 02^{\prime} 19.38^{\prime \prime} \mathrm{N}$ \\
\hline 467650 & Jiyuehtan & $120^{\circ} 53^{\prime} 59.62^{\prime \prime}$ E $23^{\circ} 52^{\prime} 58.78^{\prime \prime} \mathrm{N}$ \\
\hline 467660 & Taitung & $121^{\circ} 08^{\prime} 47.55^{\prime \prime}$ E $22^{\circ} 45^{\prime} 14.51^{\prime \prime} \mathrm{N}$ \\
\hline 467770 & Wuchi & $120^{\circ} 32^{\prime} 00.00^{\prime \prime}$ E $24^{\circ} 16^{\prime} 00.00^{\prime \prime} \mathrm{N}$ \\
\hline
\end{tabular}


Around June 10, the monsoon trough or the Mei-Yu front at the Yangtze River Basin $\left(25^{\circ}\right.$ $-30^{\circ} \mathrm{N}$ ) strengthened and rapidly progressed to the region south of the Yangtze River and persisted there until the end of June, concurring with the first severe flooding event in the region. During the week of late June to July 4, the major rain-belt moved rapidly to the Huaihe River Basin $\left(30^{\circ}-35^{\circ} \mathrm{N}\right)$. The average surface monsoon trough prevailed over the region of $35^{\circ}-40^{\circ} \mathrm{N}$ in the third episode, June 12 to July 4 , which was evident in the CWB GFS analysis but was excluded from the domain presented in Fig. 1f. During this period, the monsoon, southwesterly enhanced by the Subtropical High over the western Pacific, penetrated into Southeast China, inducing heavy rainfall in southern and southeastern China (Fig. 1e).

In early July, the monsoonal or the Mei-Yu frontal rainfall retreated from the area near the Huaihe River Basin $\left(30^{\circ}-35^{\circ} \mathrm{N}\right)$ to the Yangtze River Basin. The rainfall from mid- to late July was characterized by heavy precipitation events clustered around $28^{\circ}-30^{\circ} \mathrm{N}$ (Fig. 1g). The surface monsoon trough moved southeastward to the east of $130^{\circ} \mathrm{E}$ (Fig. 1h) due to the westward amplification of the Subtropical High, inducing the second Mei-Yu rains at the Yangtze River Basin.

Figure 2 gives a latitude-time cross-section averaged over $110^{\circ}-120^{\circ} \mathrm{E}$ for daily GPCP precipitation and 850-hPa zonal wind component of CWB GFS analysis from 1 May to 31 August. Fig. 2a shows that the rainfall migrated southward from mid-latitude in early May, inducing tropical convective-type activities around 20 May. Heavy precipitation events subsequently commenced around $15^{\circ} \mathrm{N}$ (Fig. 2a). During this onset period, the westerly winds and precipitation over the southern SCS began to move northward. This southward turning northward movement of precipitation and westerlies from early May through June formed the first clear "V-shape" signature on the cross-section in Fig. 2. In early June, the northward moving westerlies reached southern Taiwan $\left(18^{\circ}-20^{\circ} \mathrm{N}\right)$, and heavy precipitation occurred over South Taiwan. Throughout June, the Mei-Yu front continued to move northward, reaching $35^{\circ} \mathrm{N}$ at the beginning of July. The northward advancement of precipitation and westerly winds subsequently retreated southward, revisiting the Yangtze River Basin $\left(28^{\circ}-30^{\circ} \mathrm{N}\right)$ in late July. This southward movement of the system was followed by a progressively northward movement of the system to higher latitudes, forming a second "V-shape" distribution from early July through August. The precipitation and the westerlies clearly migrated hand in hand.

\section{THE EXPERIMENT DESIGN AND DATA}

The twice daily CWB GFS analysis with a horizontal resolution of $1.5^{\circ} \times 1.5^{\circ}$ and 16 pressure levels (i.e., 10, 20, 30, 50, 70, 100, 150, 200, 250, 300, 400, 500, 700, 850, 925, $1000 \mathrm{hPa}$ ) in the vertical was used for the driving base fields, as well as the initial and lateral boundary conditions.

All of the simulations were initialized from 0000 UTC May 1, 1998 and integrated continuously through August 31, 1998. Sea surface temperatures from NCEP weekly analysis were applied as the lower boundary over the ocean. Since the operational CWB GFS did not archive daily variables, such as deep soil temperatures, snow depth, soil moisture contents, albedo, etc., the surface variables are rather incomplete. Instead, historical monthly climatologies were used in this study. 


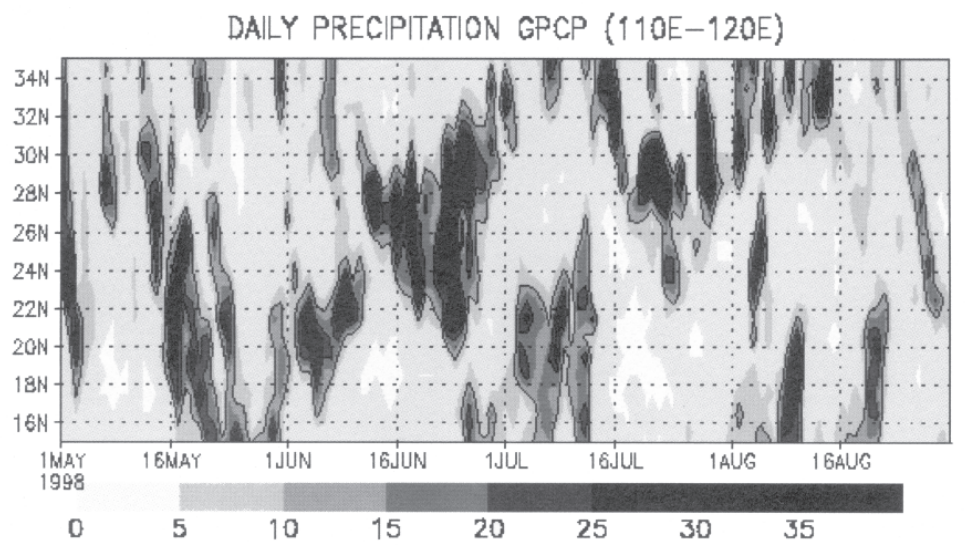

(a)

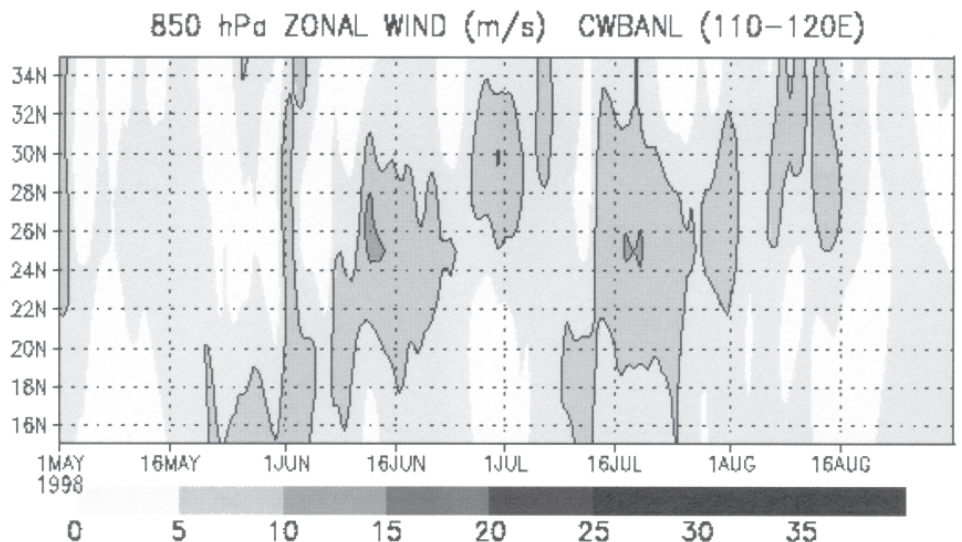

Fig. 2. Latitude-time cross-section of (a) GPCP precipitation and (b) CWB GFS $850-\mathrm{hPa}$ zonal wind analysis averaged over $110^{\circ}-120^{\circ} \mathrm{E}$ for the period of May 1 to August 31, 1998. Contour intervals are $5 \mathrm{~mm} \mathrm{day}^{-1}$ and $5 \mathrm{~m} \mathrm{~s}^{-1}$, respectively.

The first examination is to assess the model's capability to reproduce the heavy precipitation events and circulations of the 1998 East Asia Summer Monsoon evolution in various model domains. Three domains, the large (B120), the medium (M60) and the small domain (S30), were used for the sensitivity examination. The large domain simulation covers the region of $78^{\circ}-162^{\circ} \mathrm{E}$ and $17^{\circ} \mathrm{S}-55^{\circ} \mathrm{N}$ with horizontal resolution $120 \mathrm{~km}$, the medium domain covers the area of $89^{\circ}-152^{\circ} \mathrm{E}$ and $7^{\circ} \mathrm{S}-48^{\circ} \mathrm{N}$ with $60 \mathrm{~km}$ horizontally, and the smallest domain covers the region $104^{\circ}-136^{\circ} \mathrm{E}$ and $8^{\circ}-36^{\circ} \mathrm{N}$ and $30 \mathrm{~km}$ resolution horizontally. All three domains are centered at $120^{\circ} \mathrm{E}$ and $23^{\circ} \mathrm{N}$. Table 2 summarizes the setting of all simulations in this study. The model computational domains with the topography are shown in Fig. 3. For ease of comparison, only simulation results within the domain, as given in Fig. 1, will be shown in the next section. 
Table 2. Description of model settings for all simulations.

\begin{tabular}{|c|c|c|c|c|}
\hline Simulation & Grid points & Resolution & Center & Domain Covering \\
\hline B120 & $73 \times 72$ & $120 \mathrm{~km}$ & $120^{\circ} \mathrm{E}, 23^{\circ} \mathrm{N}$ & $78^{\circ}-62^{\circ} \mathrm{E},-17^{\circ}-55^{\circ} \mathrm{N}$ \\
\hline M60 & $109 \times 106$ & $60 \mathrm{~km}$ & $120^{\circ} \mathrm{E}, 23^{\circ} \mathrm{N}$ & $89^{\circ}-152^{\circ} \mathrm{E},-7^{\circ}-48^{\circ} \mathrm{N}$ \\
\hline S20 & $163 \times 158$ & $20 \mathrm{~km}$ & $120^{\circ} \mathrm{E}, 23^{\circ} \mathrm{N}$ & $104^{\circ}-136^{\circ} \mathrm{E}, 8^{\circ}-36^{\circ} \mathrm{N}$ \\
\hline S30 & $109 \times 106$ & $30 \mathrm{~km}$ & $120^{\circ} \mathrm{E}, 23^{\circ} \mathrm{N}$ & $104^{\circ}-136^{\circ} \mathrm{E}, 8^{\circ}-36^{\circ} \mathrm{N}$ \\
\hline S60 & $55 \times 54$ & $60 \mathrm{~km}$ & $120^{\circ} \mathrm{E}, 23^{\circ} \mathrm{N}$ & $104^{\circ}-136^{\circ} \mathrm{E}, 8^{\circ}-37^{\circ} \mathrm{N}$ \\
\hline
\end{tabular}

(a)

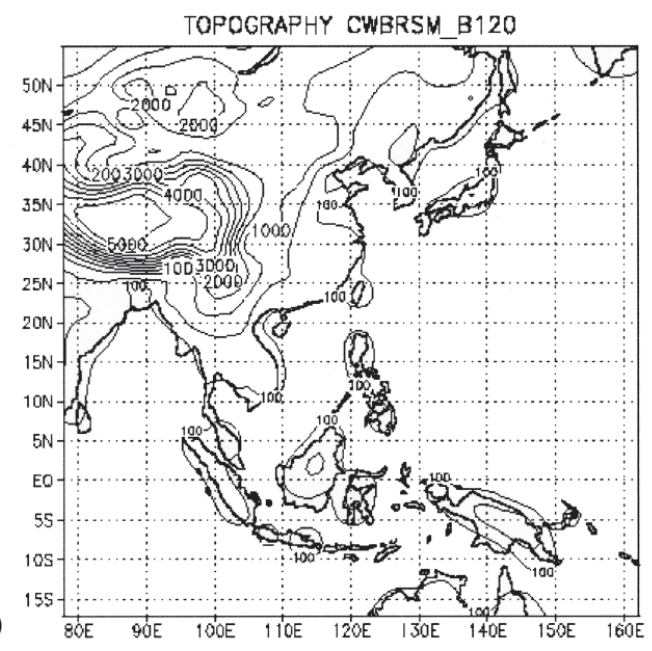

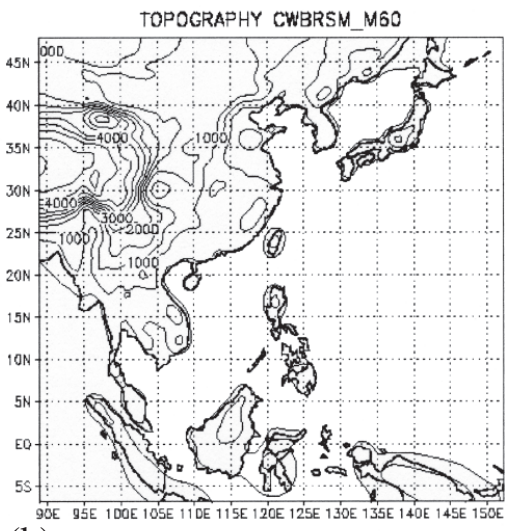

(b)

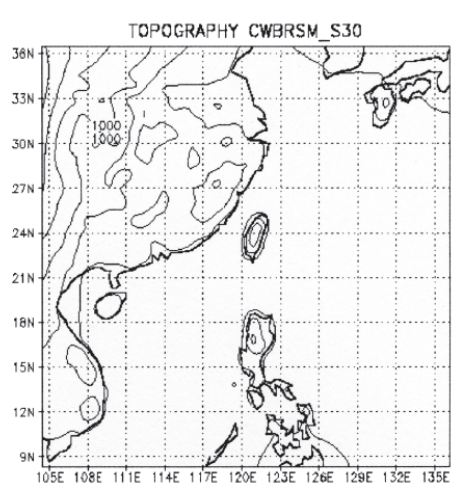

(c)

Fig. 3. The CWB RSM domains and the corresponding topography of (a) large domain B120, (b) medium domain M60, and (c) small domain S30 simulations. The contour intervals are 500 meters. 
The second experiment is a sensitivity test of horizontal resolution for simulating the detailed rainfall location over Taiwan. The simulations use the same domain as S30 but with different horizontal resolutions of 20 and $60 \mathrm{~km}$ (S20, S60).

\section{SIMULATION RESULTS}

\section{a. Sensitivity to Model Domain}

Figures 4 through 7 give the simulation results of precipitation and mean sea level pressure averaged for the four heavy rainfall episodes (onset, transition, first Mei-Yu and second Mei-Yu periods) of the 1998 summer monsoon. The panels (a), (b) and (c) show the large domain (B120), medium domain (M60) and small domain (S30) simulations, respectively.

During the summer monsoon onset period (Figs. $4 \mathrm{a}-\mathrm{c}$ ), an intensified surface low-pressure zone over the area from the SCS to southern Taiwan induced $850-\mathrm{hPa}$ westerlies or southwesterlies in this area in all simulations. The simulated $850-\mathrm{hPa}$ westerlies or

(a)

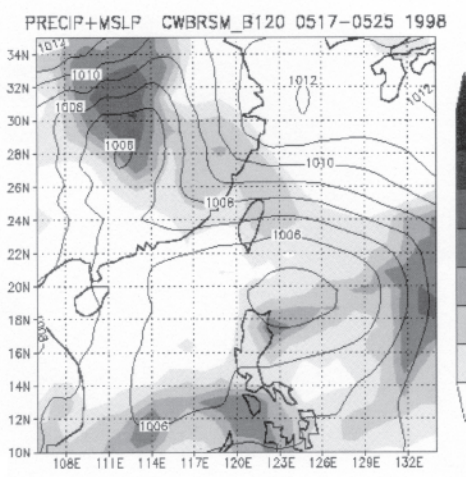

(c)

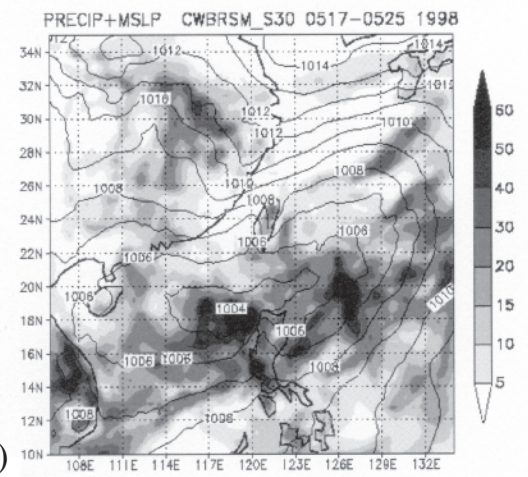

(b)

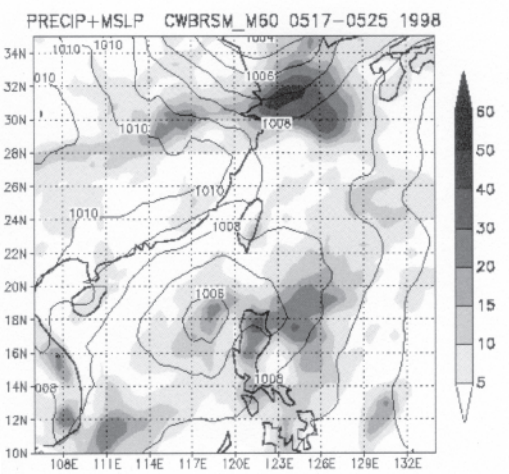

Fig. 4. Horizontal distribution of precipitation (shaded) and mean sea level pressure (contour line) for the simulations of (a) B120, (b) M60, (c) S30 during the onset period. Units of shaded area are $\mathrm{mm}^{-1 a y}{ }^{-1}$ and the pressure contour intervals are $1 \mathrm{hPa}$. 
southwesterlies were stronger than those in the CWB analysis. A cyclonic circulation was developed near the surface in both the large domain simulation (B120) and the medium domain simulation (M60). Rainfall occurred along the southern and eastern flanks of the cyclonic circulation, and intensified over the windward side of the mountain area (e.g., south SCS and east Philippines) (Figs. 4a and b). The precipitation area and amount were similar to the south branch shown in Fig. 1a, while the observed major branch over the western Pacific and the heavy precipitation over the northern SCS were not as evident. However, the precipitation over the northern SCS and the oceanic area east of the Philippines were well captured in S30 (Fig. 4c).

There are a few differences in the daily precipitation averages of 17 - 25 May between the South China Sea Monsoon Experiment observations (SCSMEX, Fig. 2b of Ding and Liu 2001) and the GPCP analysis (Fig. 1a). A heavy precipitation area along the $30^{\circ}-32^{\circ} \mathrm{N}$ with the maximum exceeding $15 \mathrm{~mm}$ day $^{-1}$ was shown in the SCSMEX, but was much lighter in the GPCP. In this experiment, both the M60 and S30 experiments simulated the rainfall area and intensity over this area like to those of the SCSMEX.

During the transition period, both B120 and M60 (Figs. 5a and b) failed to simulate the surface pressure trough due to the over-simulated cyclonic circulation strength over northeast-

(a)

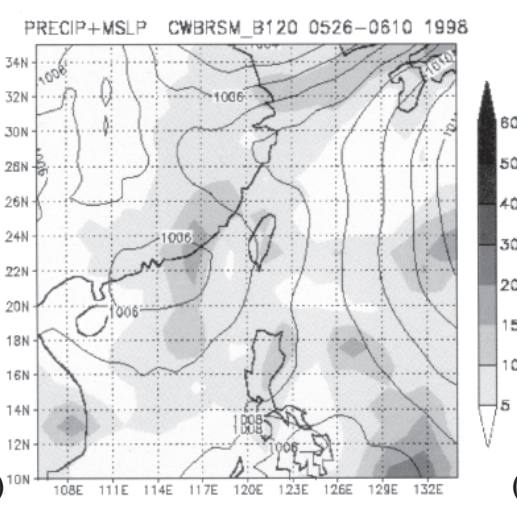

(b)

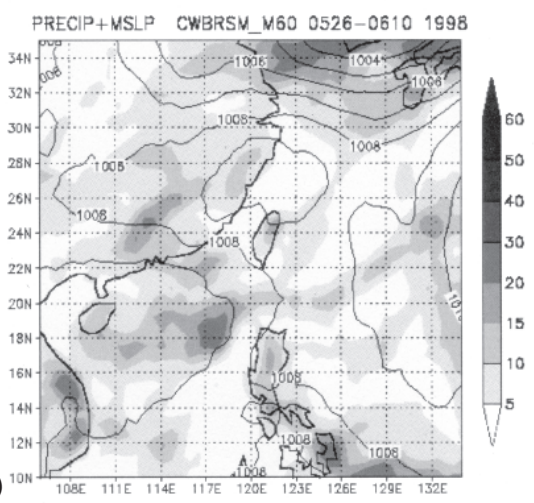

(c)

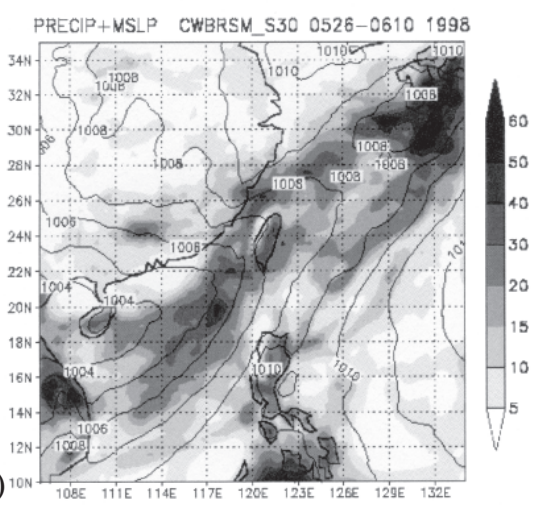

Fig. 5. Same as Fig. 4, except averaged over the transition period. 
ern Asia. The primary troughs in B120 and M60 were too weak to extend eastward beyond $120^{\circ} \mathrm{E}$. The ridge of the Subtropical High, which was shifted northward to around $25-30^{\circ} \mathrm{N}$, was unfavorable for precipitation to occur over the western Pacific. In contrast, a highly organized frontal precipitation and surface pressure trough from the SCS to southern Japan was well simulated in S30 (Fig. 5c), although the rainfall rate over the pressure trough was much higher than the GPCP analysis.

In simulations of the third episode, the ridge of the Subtropical High over the western Pacific in B120 and M60 (Figs. 6a and b) was displaced about $5^{\circ}$ northwestward compared to that in the analysis. Consequently, the simulated precipitation was pushed westward and northward. In M60, the Subtropical High over the western Pacific was relatively weaker than in B120, which allowed more rainfall to occur over inland China (Fig. 6b). However, the simulated rainfall, especially over the Yangtze River Basin, was still less than that of the analysis. S30 revealed a better simulated rainfall distribution over the Yangtze River Basin (Fig. 6c), despite a maximum precipitation rate exceeding $60 \mathrm{~mm}$ day $^{-1}$, which was much greater than the observed $20 \mathrm{~mm} \mathrm{day}^{-1}$ in GPCP and $30 \mathrm{~mm}^{-1 a y}{ }^{-1}$ in SCSMEX.

For the fourth episode, instead of a short trough just offshore of China in the analysis (Fig. 1h), a dominant ridge of the Subtropical High over the western Pacific extended southwestward from Japan to Southeast China in B120 (Fig. 7a). However, much like the analysis, a low

(a)
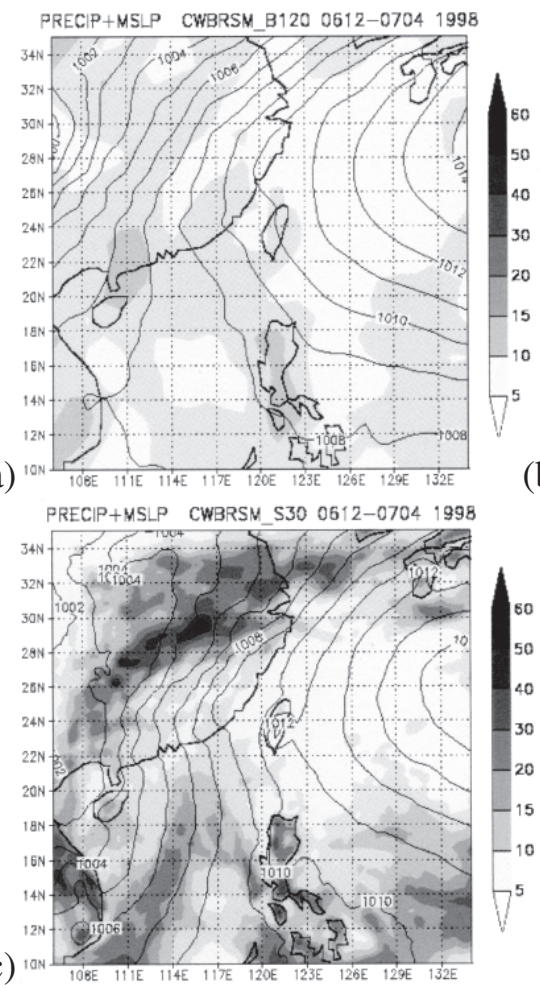

(b)

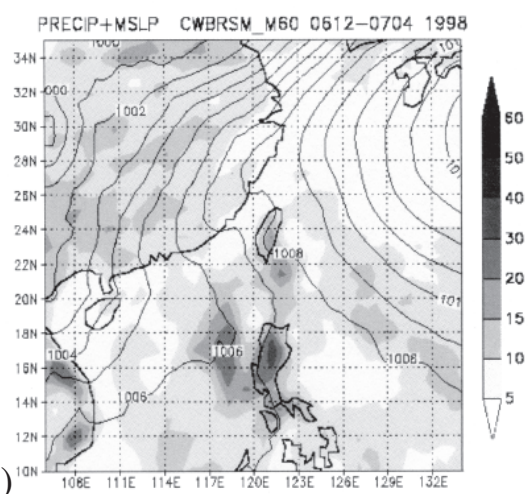

Fig. 6. Same as Fig. 4, except averaged over the first Mei-Yu period. 
pressure center over $30^{\circ}-40^{\circ} \mathrm{N}$ inland and a weaker surface pressure ridge, relative to the simulation of B120, were simulated in both M60 and S30 (Figs. 7b and c). In particular, the location of the Subtropical High over the western Pacific in the S30 was much better simulated than the simulations with larger domain (e.g., B120 and M60), despite that the simulated surface high center was situated at a slightly higher latitude than in the analysis. All simulations presented the precipitation over inland China to some degree, but also overestimated precipitation over the SCS and underestimated rainfall over the western Pacific. The precipitation over the Yangtze River Basin was still underestimated in both B120 and M60. Nevertheless, the heavy rainfall over the Yangtze River Basin was well reproduced in S30.

The latitude-time cross-section of the simulated daily precipitation (Fig. 8a) and 850-hPa zonal wind (Fig. 8b) demonstrate that $\mathrm{S} 30$ well reproduced the summer monsoon evolution of the precipitation and the low-level zonal wind when compared with the empirical observations in Fig. 2. In precipitation time series, the first "V-shape" rainfall pattern is the track of the rainband from May 10 through July 1, covering periods of southward retreat prior to the onset, commencement of the onset over SCS, northward advancement during the transition period, and the first Mei-Yu over the Yangtze River Basin (May 10 to July 1). The second "V-shape" pattern over $24^{\circ}-35^{\circ} \mathrm{N}$ represents the frontal rainfall retraction and the second visit to the

(a)

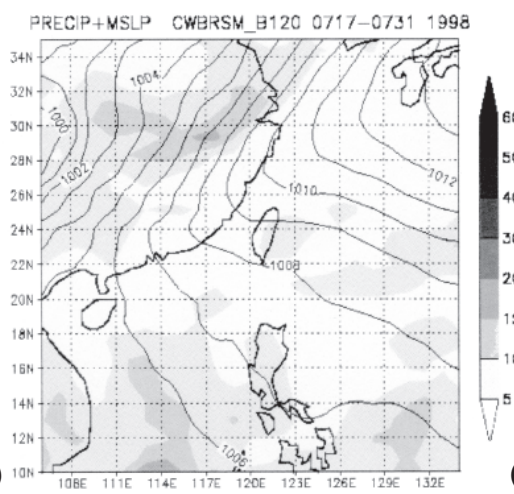

(b)

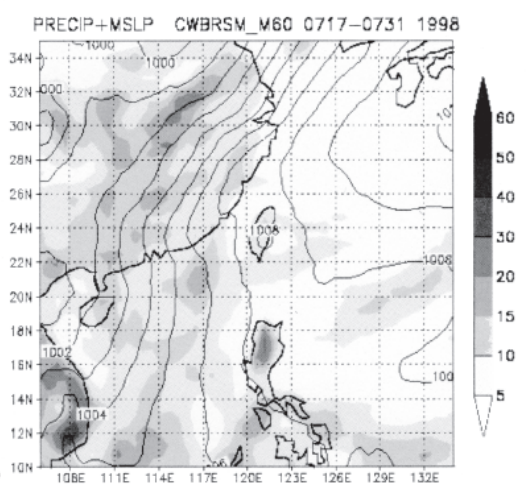

(c)

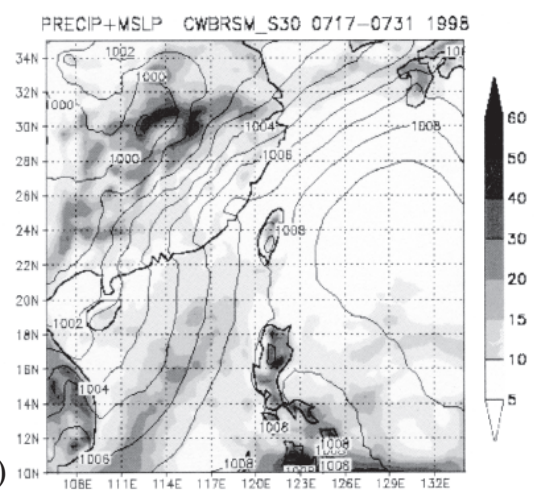

Fig. 7. Same as Fig. 4, except averaged over the second Mei-Yu period. 

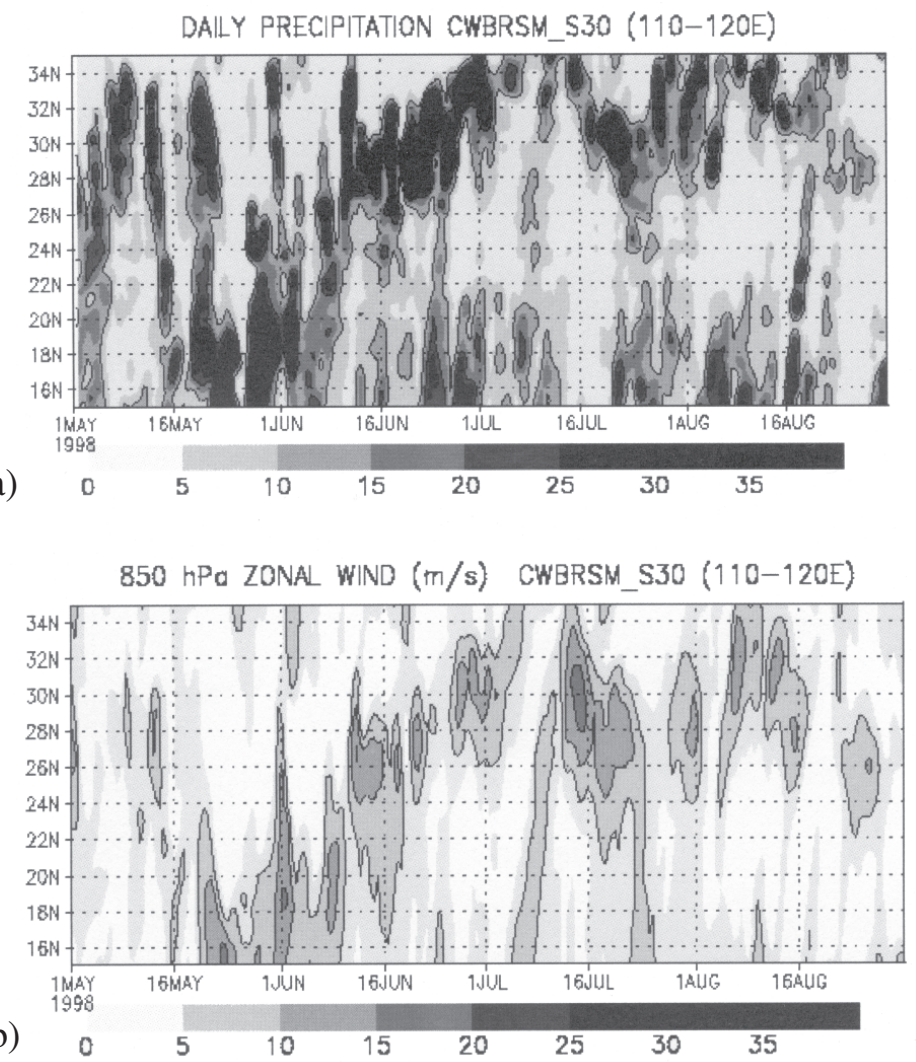

Fig. 8. Same as Fig. 2, except simulated with the S30 CWB RSM.

Yangtze River Basin (from 10 July to 16 August). Both "V-shape" signatures of precipitation on the latitude-time cross-section match the analysis well in Fig. 2a. The 850-hPa zonal wind characteristics were also well reproduced (Fig. 8b), except for a somewhat overestimated and northward displaced westerly during the first Mei-Yu front retreat period around July 16, compared to the analysis (Fig. 2b).

To detect regional characteristics using a regional model, it is necessary to use higher resolution to the analysis. Ideally, the root mean square departure (RMSD) to the analysis in the large domain B120 simulation should be smaller than M60 and S30 because the horizontal resolution in $\mathrm{B} 120(120 \mathrm{~km})$ is similar to the CWB GFS analysis $\left(1.5^{\circ} \times 1.5^{\circ}\right.$ horizontally $)$. However, in the case of CWB RSM, as shown in Fig. 9 for variables averaged over the domain $110^{\circ}-130^{\circ} \mathrm{E}$ and $15^{\circ}-30^{\circ} \mathrm{N}$ with 5 days running mean, both B120 and M60 show larger RMSD than S30 for almost all variables, including MSLP, 850-hPa temperature and 850-hPa meridional moisture flux $(\mathrm{V} * \mathrm{RH})$. Experiments B120 and M60 might have suffered from the large-scale bias described above due to their large domain size, resulting in larger RSMD than that of the S30. This finding is consistent with Jones et al. (1995) and Seth and Giorgi (1998), who used grid point models with boarder buffer zone in their studies. 
(a)
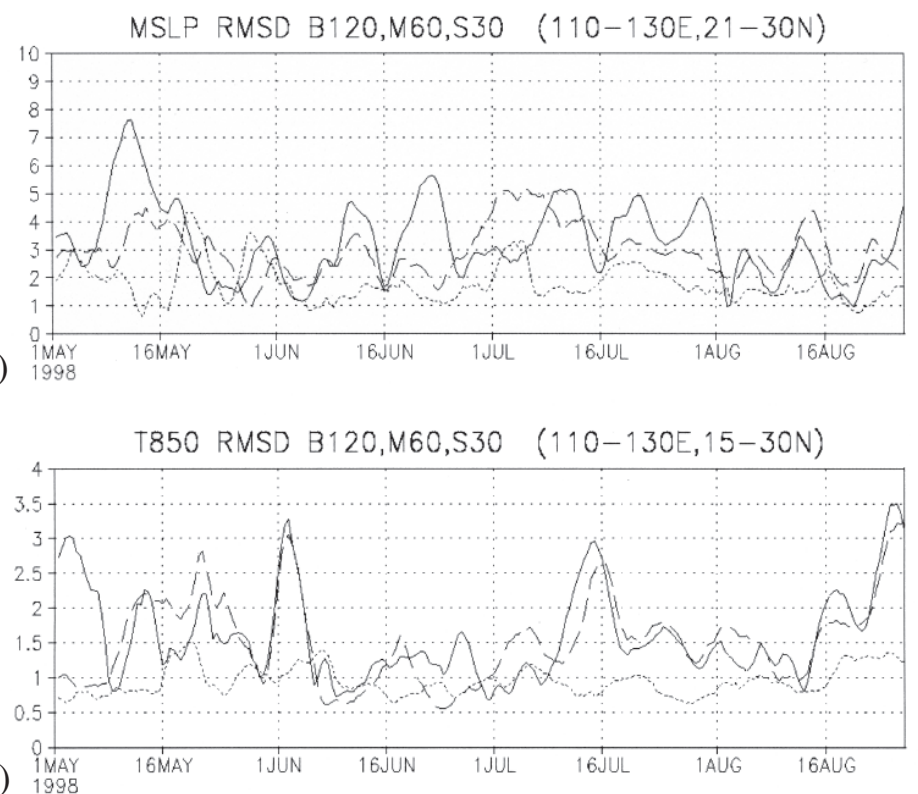

(b)

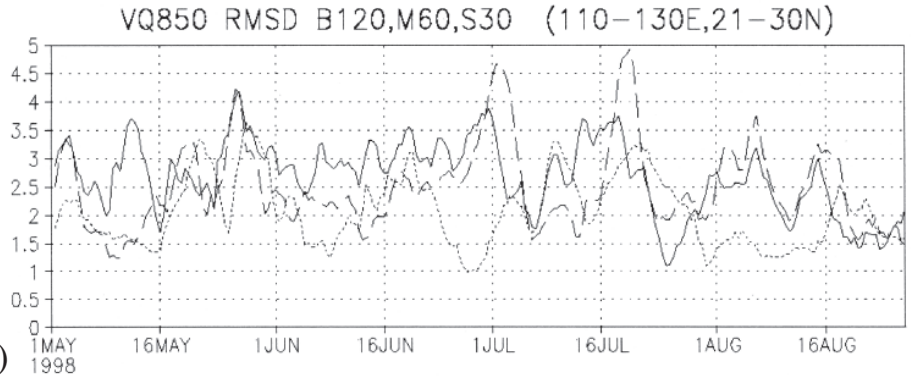

Fig. 9. The time series of 5-day running mean RMSD to analyze for (a) MSLP $(\mathrm{hPa})$, (b) $850-\mathrm{hPa}$ temperature $\left({ }^{\circ} \mathrm{K}\right)$ and (c) $850-\mathrm{hPa}$ meridional moisture flux $\left(\mathrm{kg} \mathrm{kg}^{-1} \mathrm{~m} \mathrm{~s}^{-1}\right)$ averaged over the central domain $\left(110^{\circ}-130^{\circ} \mathrm{E}\right.$, $\left.15^{\circ}-30^{\circ} \mathrm{N}\right)$. The solid line is B120, the long dashed line is M60, and the short dashed line is the $\mathrm{S} 30$ simulation.

\section{b. The Fine Resolution Phenomena}

In section 5a, better performance was demonstrated in simulation S30, the experiment with small domain and fine resolution. One may ponder which is the decisive factor, the smaller domain or the finer resolution. To address this question, simulations with identical domain, but with different resolutions of $60 \mathrm{~km}$ (S60) and $20 \mathrm{~km}$ (S20) were applied to the model for sensitivity experiments. Due to the distinct precipitation pattern during the transition period, only simulation results in this period were chosen to demonstrate the relative importance of 
domain size and model resolution in Figs. 10a and b. The findings here are consistent with those for the other periods (not shown).

The first examination compares the two simulations M60 (Fig. 5b) and S60 (Fig. 10a). Both simulations used a horizontal resolution of $60 \mathrm{~km}$ but were different in domain size. Results indicate that these two simulations show totally different primary trough and precipitation distributions, with S60 outperforming M60 when compared to the empirical data in Figs. 1c and d. Moreover, close examination of the simulations with the same domain size of S30 but with different horizontal resolutions shows that the large-scale circulations and precipitation distributions of S60 (Fig. 10a), S30 (Fig. 5c) and S20 (Fig. 10b) are similar, but that the finer structures are visible only in the higher resolution simulations. These comparisons highlight the importance of domain size in causing large-scale simulation error.

Local precipitation over the Taiwan area, however, is very sensitive to model resolution, especially when the horizontal resolution is higher than $30 \mathrm{~km}$. The first panel of Fig. 11 shows the detail of topographic contours over the Taiwan area $\left(119^{\circ}-122.5^{\circ} \mathrm{E}\right.$ and $\left.21.5^{\circ}-25.5^{\circ} \mathrm{N}\right)$ of the S30 (Fig. 11a) and S20 (Fig. 11b) experiments, respectively, where the resolved Central Range height in S20 is about 400 meters higher than that in S30.

As for simulations of the transition period, the dry area over northwestern Taiwan in S30 (Fig. 11c) is similar to S20 (Fig. 11d), whereas the rainfall over the Central Mountains is slightly higher when resolution increases. Two intense rainfall areas are simulated in S20, one over the northern Central Mountains and the other over southwestern Taiwan. However these two local centers were not evident in S30. The mean daily observed rainfall average for this period is shown in Fig. 12a, where the stations with a rainfall rate greater than $40 \mathrm{~mm}$ day $^{-1}$ are Alishan, Kaohsiung, Hengchun and Tawu. Refer to Table 2 for station locations. Intense rainfall rate areas simulated in S20 match the observations well, with the exception of northern Taiwan.

(a)

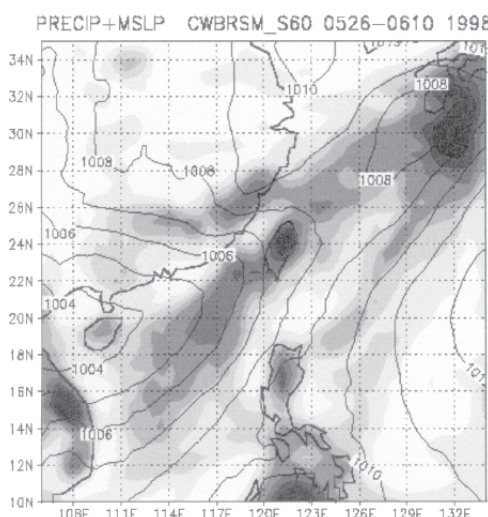

(b)

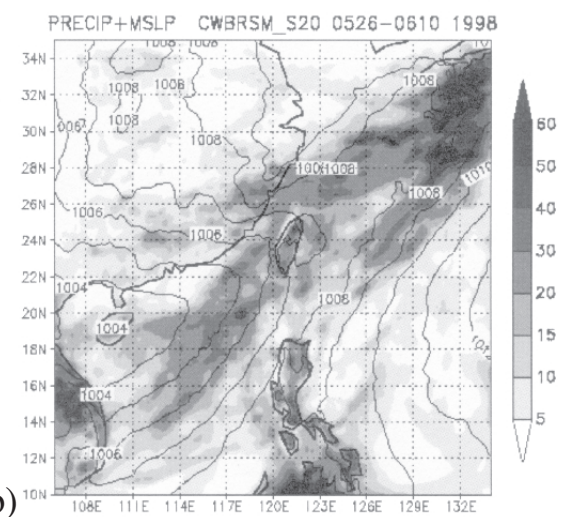

Fig. 10. Simulated precipitation (shaded) and mean sea level pressure (contour) with the small domain and model horizontal resolutions of (a) $60 \mathrm{~km}$ (S60) and (b) $20 \mathrm{~km}$ (S20), averaged over the transition period. Units of shaded area are $\mathrm{mm} \mathrm{day}^{-1}$ and contour intervals are $1 \mathrm{hPa}$. 


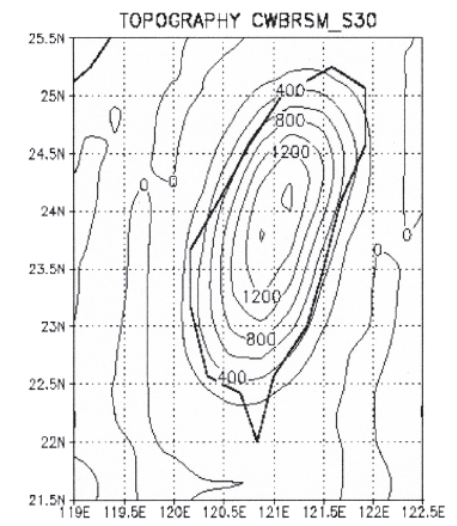

(a)

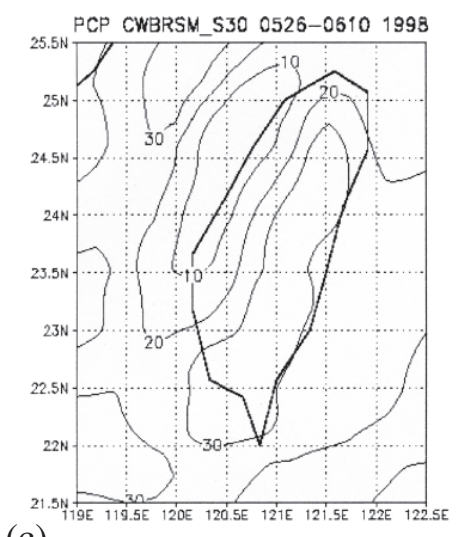

(c)

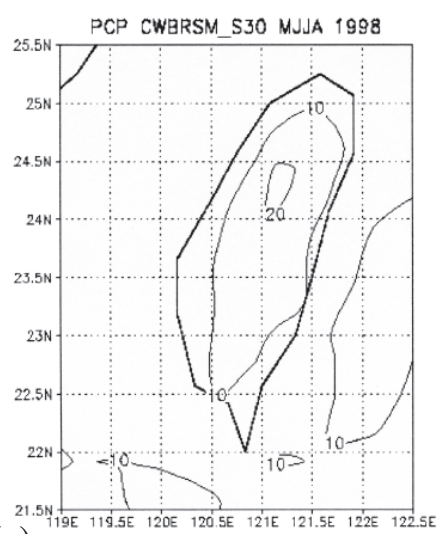

(e)

(f)

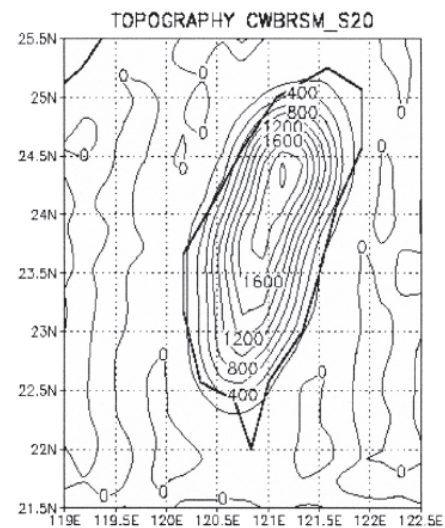

(b)

(d)
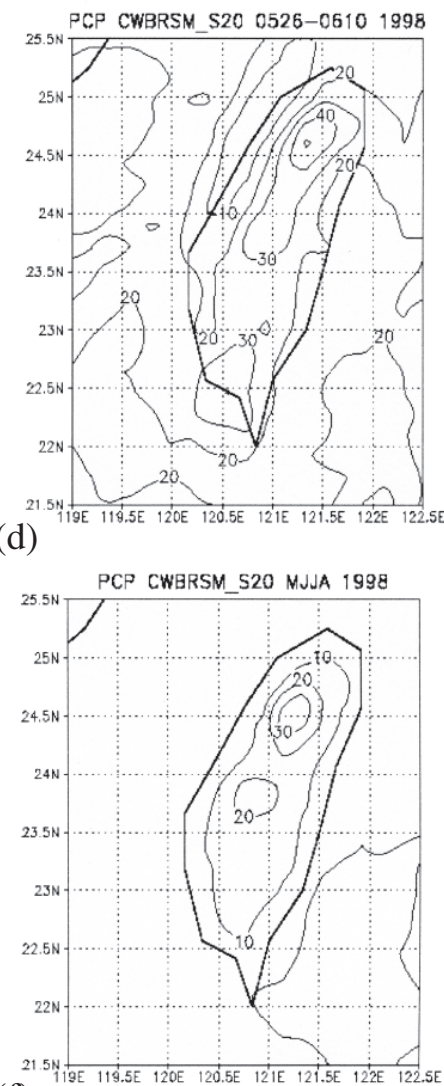

Fig. 11. Monthly averaged daily precipitation of S30 (left panels) and S20 (right panels) simulations, where $(a, b)$ show the topography elevation with contour interval of 200 meters, (c, d) show the simulated precipitation averaged over the transition period $\left(\mathrm{mm} \mathrm{day}^{-1}\right)$, and $(\mathrm{e}, \mathrm{f})$ show the simulated precipitation averaged over MJJA $1998\left(\mathrm{~mm} \mathrm{day}^{-1}\right)$. 
Local precipitation maxima over the northern Central Mountains were evident not only during the transition period, but also in the seasonal mean from May through August, as shown by the S20 simulation (Fig. 11f). The S20 simulation showed an additional local precipitation extreme in central Taiwan= whereas S30 caught only the event over northern Taiwan (Fig. 11e). It seems that the heavy rainfall areas in S20 are rather consistent with the observations at Taipei, Yushan and Alishan in the northern and the Central mountain areas on seasonal average, but do not agree as well with conditions in southern Taiwan (Fig. 12).

The CWB RSM, even with $20 \mathrm{~km}$ resolution, lacks some characteristics of heavy rainfall over southern Taiwan. This modeling defect is partly due to the model's inability to simulate extreme precipitation events. For example, the observed daily extreme rainfall amounts of $311.5 \mathrm{~mm}$ on June 4 at Hengchun, Tawu $274 \mathrm{~mm}$ on June 5, Alishan $254 \mathrm{~mm}$ on June 8, and Kaohsiung $221.5 \mathrm{~mm}$ on June 6, were missed altogether in the S20 simulation (not shown). Increasing the model resolution and incorporating detailed surface information through a much more thorough surface hydrological scheme might be needed for the CWB RSM to simulate such severe precipitation phenomena accurately.

\section{SUMMARY AND DISCUSSION}

The Taiwan Central Weather Bureau (CWB) regional spectral model (RSM) is a newly developed model for regional climate downscaling forecasts at CWB. To assess the accuracy

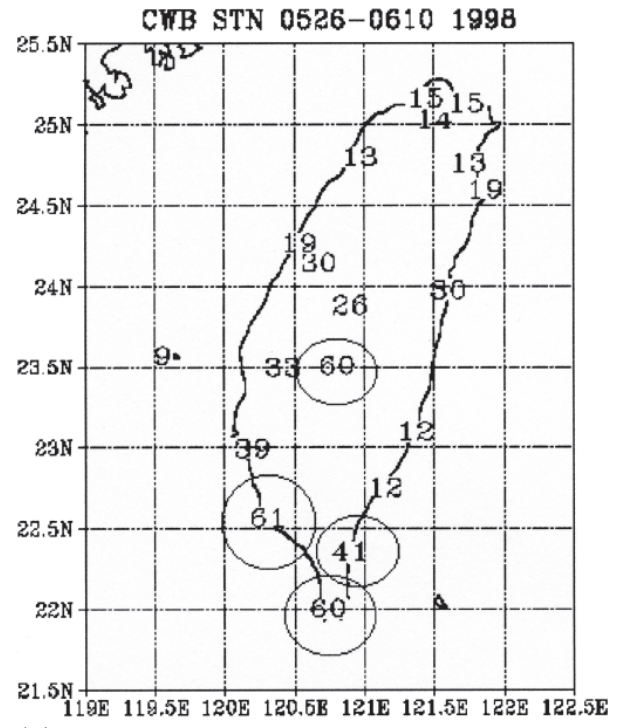

(a)

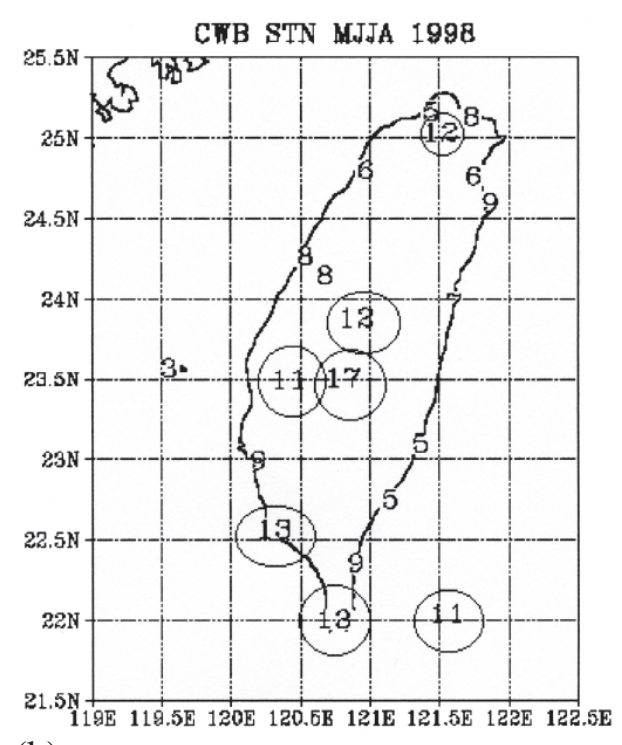

(b)

Fig. 12. Observed precipitation at CWB stations averaged over (a) the transition period and (b) MJJA of 1998. Units are mm day ${ }^{-1}$. 
of CWB RSM, sensitivity simulations of the domain covering and horizontal resolutions for the 1998 East Asia Summer Monsoon evolution were carried out in this study.

All the simulations were conducted from May 1 through August 31, with the initial and lateral boundary conditions taken from the analysis of the CWB global forecast system. Four identified episodes during the evolution of the 1998 summer monsoon and the associated Mei$\mathrm{Yu}$ precipitations were chosen for simulation. Three followed the description given by Ding and Liu (2001) and Wang et al. (2003); an additional period specifically for the Taiwan area was selected for the evaluation of simulations. These four periods are characterized by 1 ) the monsoon onset period over the SCS during 17 - 25 May; 2) the additional transition period when the Mei-Yu front moved from SCS to mid-latitude during late May to early June; 3 ) the first visit of the Mei-Yu front to the Yangtze River from June 12 to July 4; and 4) after a retreat, the second visit of the Mei-Yu front to the Yangtze River during 17 - 31 July.

In the sensitivity simulations of large domain (B120), medium domain (M60) and small domain (S30), the S30 simulation outperformed the other two in all four episodes. S30 well simulated not only the circulation pattern on all periods, but also the precipitation distribution over the SCS and the monsoonal rain-belt over the western Pacific during the onset and transition periods, even though the rainfall intensity was somewhat overestimated. The heavy precipitation events associated with the first and second visits of Mei-Yu to the Yangtze River Basin $\left(25^{\circ}-30^{\circ} \mathrm{N}\right)$ were also well reproduced in $\mathrm{S} 30$, but precipitation over the western $\mathrm{Pa}$ cific and the SCS were not. The 5-day running mean of RMSD of various meteorological variables over the central domain confirmed that the larger domain simulations caused significant large-scale deviation from the driving analysis. As suggested by Jones et al. (1995) and Seth and Giorgi (1998), too many uncertainties occur when the lateral boundary forcing is weak and the degree of freedom of the interior domain increases in large domain simulations. The results from this experiment are mostly consistent with that suggestion; however, since the forcing large-scale circulation is imposed in the whole domain of our model, lateral boundary forcing may not be the only forcing source. The weak boundary forcing and a high degree of freedom in the interior domain alone do not explain completely the large-scale biases in our simulations. More future sensitivity experiments are needed to identify possible cause or causes of biases in the CWB RSM.

To highlight the relative importance of domain size and model resolution, we compared two pairs of simulations. The first pair, M60 and S60, had the same $60 \mathrm{~km}$ resolution but different domain size; the second pair, S60 and S30, shared the same domain size but had different resolutions. We demonstrated that the simulated large-scale circulation and precipitation distribution were more sensitive to the model domain size than to the model horizontal resolution. However, the finer structures could only be captured in the higher resolution simulations.

The simulation with $20 \mathrm{~km}$ resolution reproduced the local heavy rainfall areas over the northern Central Mountains quite well when compared with the empirical station observations for both the transition period and the MJJA average. Although the simulation captured the heavy rainfall phenomena of southern Taiwan during the transition period, the $20 \mathrm{~km}$ resolution may still be insufficient to resolve accurately the fine features of the local severe precipitation quantitatively. 
Since simulations with large domain size covering the East Asian area produce largescale biases, and simulation with resolution higher than $20 \mathrm{~km}$ is too expensive computationally to develop regional climate downscaling forecasts operationally, the S20 simulations represent, at best, a preliminary and temporary solution for the CWB RSM downscaled climate simulations. Many caveats in the experiments are still evident in this study. For example, the use of climatology instead of daily analysis in surface variables might reduce the higher temporal frequency surface forcing as well as the inter-annual surface variation to the simulations. Also, fine-scale validation was not possible due to the lack of station observations over China. These deficiencies should be addressed by more detailed studied in the future.

Another important issue related to model resolution, suggested by Giorgi and Marinucci (1996), is the effect of scale-dependent physical forcing (e.g., topography), which can be strongly modulated by the model resolution. For example, the horizontal resolution used in CWB RSM is much smaller than that in the current global weather forecast model (T120) but the physical packages are the same. The current physical parameterizations might not be sufficiently sensitive to identify the local phenomena. The implementation of the prognostic cloud scheme is the next step in improving the CWB RSM.

Acknowledgments This research was supported by the Research and Development Center at the Central Weather Bureau, Taiwan. We owe gratitude to Ms. Diane Boomer for improving the readability of the manuscript. We also wish to extend our thanks to Dr. Shyh-Chin Chen and two other anonymous reviewers for their instructive suggestions.

\section{REFERENCES}

Dickinson, R. E., R. M. Errico, F. Giorgi, and G. T. Bates, 1989: A regional climate model for the western United States. Climate Change, 15, 383-422.

Ding, Y. H., and Y. Liu, 2001: Onset and the evolution of the summer monsoon over the South China Sea during SCSMEX field experiment in 1998. J. Meteor. Soc. Japan, 79, 255-276.

Giorgi, F., and G. T. Bates, 1989: The climatological skill of a regional model over complex terrain. Mon. Wea. Rev., 117, 2325-2347.

Giorgi, F., and M. R. Marinucci, 1996: An investigation of the sensitivity of simulated precipitation to model resolution and its implications for climate studies. Mon. Wea. Rev., 124, 148-166.

Giorgi, F., M. R. Marinucci, and G. T. Gates, 1993: Development of a second-generation regional climate model (RegCM2). Part I: Boundary-layer and radiative transfer processes. Mon. Wea. Rev., 121, 2794-2813.

Gong, W., and W. C. Wang, 2000: A regional model simulation of the 1991 severe precipitation event over the Yangtze-Huai River Valley. Part II: Model bias. J. Climate, 13, 93108.

Hong, S. Y., and H. M. H. Juang, 1998: Orography blending in the lateral boundary of a regional model. Mon. Wea.Rev., 126, 1714-1718. 
Huffman, G. J., R. F. Adler, P. Arkin, A. Chang, R. Ferraro, A. Gruber, J. Janowiak, A. McNab, B. Rudolf, and U. Schneider, 1997: The Global Precipitation Climatology Project (GPCP) combined precipitation dataset. Bull. Amer. Meteor. Soc., 78, 5-20.

Ji, Y., and A. D. Vernekar, 1997: Simulation of the Asian summer monsoons of 1987 and 1988 with a regional model nested in a global GCM. J. Climate, 10, 1965-1979.

Jones, R. G., J. M. Murphy, and M. Noguer, 1995: Simulation of climate change over Europe using a nested regional-climate model. Part I: Assessment of control climate, including sensitivity to location of boundaries. Quart. J. Roy. Meteor. Soc., 121, 1413-1450.

Juang, H. M. H., and M. Kanamitsu, 1994: The NMC nested regional spectral model. Mon. Wea. Rev., 122, 3-26.

Juang, H. M. H., S. Y. Hong, and M. Kanamitsu, 1997: The NCEP regional spectral model: An update. Bull. Amer. Meteor. Soc., 78, 2125-2143.

Juang, H. M. H., and S. Y. Hong, 2001: Sensitivity of the NCEP regional spectral model on domain size and nesting strategy. Mon. Wea. Rev., 129, 2904-2922.

Juang, H. M. H., C. H. Shiao, and M. D. Cheng, 2003: The Taiwan Central Weather Bureau regional spectral model for seasonal prediction: Multiparallel implementation and preliminary results. Mon. Wea. Rev., 131, 1832-1847.

Kato, H., H. Hirakuchi, and K. Nishizawa, 1999: Performance of NCAR RegCM in the simulation of June and January climates over eastern Asia and the high-resolution effect of the model. J. Geophys. Res., 104, 6455-6476.

Kida, H., T. Koide, H. Sasaki, and M. Chiba, 1991: A new approach to coupling a limited area model with a GCM for regional climate simulations. J. Meteor. Soc. Japan, 69, 723-728.

Lau, K. H., A. Y. Wang, Y. H. Kuo, S. J. Chen, and J. Dudhia, 1998: The evolution of the East Asia summer monsoon in June 1994: Numerical simulations. J. Meteor. Soc. Japan, 76, 749-764.

Liou, C. S., J. H. Chen, C. T. Terng, F. J Wang, C. T. Fong, T. E. Rosmond, H. C. Kuo, C. H. Shiao, and M. D. Cheng, 1997: The second-generation global forecast system at the Central Weather Bureau in Taiwan. Wea. Forecasting, 12, 653-663.

Liu, Y. Q., F. Giorgi, and W. M. Washington, 1994: Simulation of summer monsoon climate over East Asia with an NCAR regional climate model. Mon. Wea. Rev., 122, 2331-2348.

Seth, A., and F. Giorgi, 1998: The effects of domain choice on summer precipitation simulation and sensitivity in a regional climate model. J. Climate, 11, 2698-2712.

Von Storch, H., E. Zorita, and U. Cubasch, 1993: Downscaling of global climate change estimates to regional scales: An application to Iberian rainfall in wintertime. J. Climate, 6, 1161-1171.

Waldron, K. M., J. Peagle, and J. D. Horel, 1996: Sensitivity of a spectrally filtered and nudged limited area model to outer model options. Mon. Wea. Rev., 124, 529-547.

Wang, Y., O. L. Sen, and B. Wang, 2003: A highly resolved regional climate model (IPRCRegCM) and its simulation of the 1998 severe precipitation event over China. Part I: Model description and verification of simulation. J. Climate, 16, 1721-1738.

Shiao, C. H., and H. M. H. Juang, 2006: Sensitivity study of the climate simulation over east Asia with the CWB regional spectral model. Terr. Atmos. Ocean. Sci., 17, 593-612. 